\title{
The Development Of Expert Learners In The Classroom
}

\author{
Saemah Rahman, Universiti Kebangsaan, Malaysia \\ Zuria Mahmud, Universiti Kebangsaan, Malaysia \\ Siti Fatimah Mohd Yassin, Universiti Kebangsaan, Malaysia \\ Ruslin Amir, Universiti Kebangsaan, Malaysia \\ Khadijah Wan Ilias, Universiti Kebangsaan, Malaysia
}

\begin{abstract}
The term 'expert learner' refers to students who are actively engaged with the materials learned and take responsibility for their own learning. Literature reviews suggested the use of metacognitive approach to help develop students to become expert learners. Research on development of expert learners can be traced from movements that focused on the importance of learning strategies and "learning how to learn" approach. Some researchers combined the role of teachers and students in formulating a framework on how to develop expert learners. This study aimed to identify issues related to the development of expert learners in the classroom. Data were collected from focus group with students and teachers in Malaysia. Findings were reduced into thematic categories representing students' and teachers' perceptions on the issues. Results of the study showed that the use of metacognitive strategies among students is very minimal and many teachers did not aware the benefit of making the learning process visible to students. The implementation of "learning to learn" approach in the teaching and learning process remain one of the key problem need to be address in order to help students learn effectively in the classroom.
\end{abstract}

Keywords: expert learner, learning how to learn, metacognitive strategies

\section{INTRODUCTION}<smiles></smiles>

tudents need study skills in order to learn effectively. However, one important question for educators to ask is to what extent do these students are adequately equipped with the learning skills needed. In other words, to what extent do we support the development of expert learners amongst our students. Review of literature showed that the emphasis on "learning how to learn" is not an agenda in the school classroom (Woolfolk,2008). Teachers generally focus on the teaching of content and neglect the process students encounter as the learning takes place. This practice ignores the valuable process that should be exploited to help students develop their learning skills. Research in study skills revealed that generally students acquire study skills through trial and error without formal training or guidance that can expedite their grasp of what and how to approach learning effectively.

The term 'expert learner' refers to students who can learn effectively in their learning process. Zimmerman (2000) assert that expert learner plan, set goals, organize, self-monitor and self-evaluate at various points during the process of knowledge acquisition. Expert learners set reasonable learning goals for themselves and have the selfefficacy to choose and use productive learning strategies. These strategies then result in learning gains. Moreover, expert learners can be taught and their ability to learn can improve over time (Aronson, Fried \& Good, 2002; Blackwell, Trzesniewski \& Dweck, 2007). Ertmer \& Newby (1996) describe expert learner as people who display planfulness, control, and reflection which help them to be aware of the knowledge and skills they possess, or are lacking, and consequently, use appropriate strategies to actively implement or acquire them. They define expert learners as strategic, self-regulated, and reflective learners. They also suggested a model of expert learning which illustrates how learners' metacognitive knowledge of cognitive, motivational, and environmental strategies is translated into regulatory control of the learning process through ongoing reflective thinking. The emphasis of their 
model is on how we can make the students consciously aware of their learning process so that they can monitor and control their thought processes, and inevitably become learners who are able to perform at a more expert level.

Woolfolk (2008) listed three characteristics of expert learners that showed how far students are actively engaged with the materials they learn namely: 1) they focus their attention on materials learned, 2) they give effort to process the information deeply, and 3) they take responsibility for their own learning. These characteristics are not built automatically but are deliberately planned and monitored to achieve the learning objectives. It is suggested that developing expert learner needs a deliberate effort geared towards creating awareness and procedural knowledge on how to implement and manage learning activities.

Research on development of expert learners can be traced from movement that focused on the importance of learning strategies and "learning how to learn" approach. The essential part in developing expert learners lies in the use of an approach that enables students to be aware of elements that affect the effectiveness of their learning process. One of the approach suggested by educational psychologists to help students become expert learners is metacognitive approach (Borkowski \& Krause, 1985; Schraw \& Brooks, 1999, Woolfolk, 2008). It is suggested that the development of general strategies to approach learning can be developed simultanouesly as they learn the content of subject matter (Borkowski \& Krause, 1985). Metacognitive strategies involves three processes that help students control their learning process. They are: 1) planning, 2) monitoring and 3) evaluating. These three steps can control the learning process through a series of questions that requires students to do self assessments about the learning task they are trying to solve.

Two types of knowledge needed by students to employ metacognitive process are: 1) procedural knowledge and (2) conditional knowledge. Procedural knowledge refers to an understanding of how to perform various cognitive activities while conditional knowledge refers to knowledge of when and why to apply a strategy (Woolfolk, 2008). Beyer (1987) suggested the use of metacognitive reflection to make learning processes explicit to students in the effort to make them aware of what they are going through. This experiences help them acquire the 'learning how to learn' skills. Knowing these two types of knowledge will enable them to plan, monitor and evaluate their learning process. It is hypothesized that the implementation of metacognitive approach will increase students awareness about how to approach a given learning situation. This approach provide students with the opportunity to acquire and develop as much procedural and conditional knowledge thus helping them to become expert learners. The emphasis of metacognitive approach is to help students become expert learners who can plan, monitor and evaluate their own learning process.

This paper discusses issues related to the development of expert learner from students and teachers perspectives. Results of the study is hoped to give insights in developing module that can be used by teachers to help students becomes expert learners.

\section{METHODOLOGY}

This study employed qualitative data collection namely focus group interview to gather data on the issues related to the development of expert learners in the classroom. Sample for students were selected from Form four students in Malaysian secondary schools (equivalent to $10^{\text {th }}$ grade) (4 groups of eight students from 4 schools, $\mathrm{N}=32$ ), meanwhile sample for teachers were selected from the teachers in the selected schools above (four groups of 4 teachers (Science, Mathematics, Language and History teachers) from each school, $\mathrm{N}=16$ ). Interview protocols for both types of samples were developed based on metacognitive framework which include metacognitive knowledge and awareness, and component of metacognitive strategies namely planning, monitoring and evaluation of learning process in the classroom. The focus of the interview was on the characteristic of expert learners and teachers' initiatives to develop expert learners in the classroom. Data from the interviews were transcribed and coded using NVivo 7. Findings were reduced into thematic categories representing students and teachers perceptions regarding issues related to the development of expert learners. 


\section{RESULTS}

The results of the focus group interview provide information regarding students' and teachers' perceptions about issues related to the development of expert students namely: i) The characteristics of expert learner, and ii) Teachers' initiatives to help students become expert learners in the classroom. These aspects were explored to gauge the extent of the development of expert learner in the classroom. Results will be reported in relation to these aspects.

\section{Characteristics of expert learners}

Students' as well as teachers' perspective on the meaning of learning will affect how they approach learning in the classroom. It is important that they are aware of what learning means and what is expected from the process. Understanding what is happening in the learning process in the classroom is important to gauge the extent of expert learner development in the classroom. Within this framework, teachers were asked questions on what they expect their students would do in the classroom and to describe the situation they are facing in the classroom in relation to the characteristics of the expert learners.

The data showed some discrepancy between students and teachers on what is expected in the learning process in the classroom. Teachers expect that students should be ready to involve in the learning process by preparing themselves before the class start. One of the teachers stress the importance of students to read the topic before class so that they have basic knowledge that help them to understand what will be taught in the classroom. This view is supported by another teacher who concluded: "The students should be ready for learning... they should read before coming to class...". But the teachers claimed that most of the students do not meet this expectation especially students in the weaker class. Therefore, the students face difficulty in understanding the concept taught. The teacher also claimed that students regarded learning just as receiving from teachers. Among the claims by teachers are:

“...They just receive.... for exam......"

".... just receive from teachers...."

"they depend $100 \%$ on teachers..."

"they are not ready to learn... ".

"No self initiative.... Just waiting to be spoon-fed by teachers...."

The teachers also stress the important of attention in the learning process. The teachers regarded focusing attention as the most important elements in the classroom but concluded that getting students' attention is the biggest challenge especially in the weaker class. One teacher claim: "... most of the time students tend to lose their attention during the learning process.... Especially after 15 or 20 minutes of lesson...". One female teacher pointed out that she has to be a "step mother" to get attention from the students. "... I told my students that I am their step mother... I give warning to them... if they don't pay attention, they will be punished...."

The teachers also concluded that some students don't even bother to find out what is happening and some are attending classes because they are expected to do so. It can be concluded that the common agreement among the teachers are that the students lack of initiative and just doing what is instructed by the teachers. Data from focus group interview with the students provide support to the claim made by the teachers. Generally, students regarded learning as listening to what the teachers said. The students reported that they just follow what the teachers ask them to do. Among the claims are:

".. I just try to listen to what the teachers said..."

"I just listen to teachers and take notes....

"I just follow what the teachers ask us to do..."

Most of the students revealed that they just try to follow what the teacher asked them to do without really understanding what they are doing or why they have to do it. 
The common problem cited by the students is they do not understand what teachers are teaching. Only a few students reported that they do ask explanation from teachers in the classroom if they don't understand but majority said they seldom ask teachers in the classroom. One male student said: “... I seldom ask..... because I am shy... as there are many girls in the class...”. Another male respondent pointed: “... I don't know what to ask....”. In relation to this, one important aspect related to the characteristic of expert learner is the effort to deeply process the information learned. The teachers admitted that students did not give effort to process information deeply if they are not prompted to do so. When asked to give examples, students always depend on what was written in the text book. They failed to elaborate and relate what is learned with their own experience thus failed to give their own examples which is very important to help them understand the materials learned. One teacher asserted: ".... I have to give a lot of examples....., and give a lot of exercises...". As a whole, the data shows that most students seldom do deep processing on the materials learned in the classroom.

Issues on the extent of students taking charge of their own learning can be analyzed through the practice of three metacognitive processes namely: planning, monitoring and evaluation. Planning the learning activity is related on whether the students are aware of their learning goal and consciously plan the strategy to achieve the learning goals. It should be followed by the monitoring and evaluation processes to keep track whether they have achieved the desired learning goals. The first step in planning activity is the awareness on the objective of the learning activity. The data showed that most teachers agreed that basically students are not aware of the goal of learning and just follow on the activities set and planned by teachers. Among the claims are:

".....normally the students did not have any particular objectives...."

“.... So far I don't see any students aware of the goal of learning......"

"..... we just tell them the topic...."

"... even if we ask them to see the objective, they just wait from teachers...."

The teachers agreed that the students are not trained to focus on the objective of the learning activity. The teachers also reported that they did not spell out explicitly the objective of the lesson, but agreed that it is important for the students to know the objectives. The teachers are very skeptical when asked whether students are aware and deliberately do the planning, monitoring and evaluating their learning process.

“... its hard to see students plan their learning process ..."...

“...I don't see any of the students monitor their learning process...."

"..... the teacher need to instruct them..."

"... just through the score they got from the quiz or test...."

"... the students seldom do self-assessment on their own..."

The study revealed that the normal procedure in the classroom is the teacher will introduce the topic and plan the activity for students. Assessments are usually done by the teacher at the end of the class through exercises, quiz or 'Question and Answer' session. However, the respondents agreed that teachers can guide students on the strategies to achieve the objective and eventually help them to monitor and evaluate the achievement of the objective.

\section{Teachers' initiatives to help students become expert learners}

Teachers were asked about skills needed by students to learn effectively in the classroom and how do the teachers help students acquire the skills. Two main categories emerged from the data. Most teachers agreed that learning process involves skills needed in the knowledge construction process which can be categorized into two broad categories namely: 1) general skills and 2) domain specific skills.

The skills that every student should possess are the information processing skills as well as information organization skills. The general skills include reading skills, listening skills and note taking skills. The information processing skills may be general, which can be used across the discipline, but some may be specific to a certain subject or content areas. Among the specific skills cited by Language teachers are summarizing, describing and relating. Meanwhile the History teachers suggested finding and organizing information as important skills in 
History. The Science Teachers proposed many skills such as building hypothesis, making inferences, making observations during experiment, comparing and contrasting, predicting and making conclusions. Meanwhile the Mathematic teachers mainly cited the importance of problem solving skills.

When asked whether the students possess the skills needed to learn effectively in the classroom, the general remarks were very negative. One teacher complained: "...they should have the reading skills... but they are very slow... The teachers have to explain everything...." The respondents were also asked about their initiative to help students 'learn how to learn'. One teacher said: “... just teach... normally I give them note.....". Among the activities done in the classroom cited by teachers are:

“... I do quiz, simplify the notes in the form of table, flow chart, give guidelines and give examples how to answer/solve problem....."

“...give examples, ask students to try to do on their own, and ask questions at the end of session...."

Majority of the teachers focused their efforts to help students do well in their examinations. This effort can be trace from their responses which showed the emphasis of learning activity in the classroom as follows:

“....So far, I just use past years question to help them..."

"....I give more exercises, drills focusing on examination....."

"...For the weaker class, focus on the easiest part and drill to help them pass the examinations ..."

"....focus on past year questions..."

The data also shows that making 'learning how to learn' explicit is not an agenda among the respondents. Most of the respondents were skeptical about the process and more concern about the time constraint. The teachers seem too occupied with the burden of completing the syllabus. It can be concluded that teachers are not aware the importance of making learning process explicit to students. The general responses by teachers are:

“.... I just give note.... Then I explain, followed by giving students exercises..."

"....after teaching.... I give exercise and who don't understand can come and see me..."

"... I teach them step by step...."

“... Just discuss after a test ... so that we know their weaknesses... and explain how to do...."

For the generic learning skills like reading skills and note taking skills, most respondents agreed that support system, namely the guidance and counselling service should take initiative to train students how to read and make notes, but teachers also agreed that some domain specific skills like problem solving skills in the subject matter areas should be made explicit by teachers while teaching the content. It can be concluded that most teachers agreed that teachers can play their role in helping students be aware of the learning process. One teacher admitted that he saw the important of making the learning process explicit to students: "Yes... I think it can help them learning how to learn...”.

\section{DISCUSSION}

Results of the study showed some discrepancy between students and teachers on what is expected in classroom learning process. Generally teachers agreed that students need certain skills in order to learn effectively. However students encountered problems in giving attention to the material learned in the classroom. Results of this study shows that generally students failed to deeply and meaningfully process the information learned. Activities in the classrooms are geared specifically towards the content that what will be asked in the examination. This approach limits teachers' opportunities to help students become expert learners. At the same time, it also positions the students in surface learning which can be detrimental to the consequent of learning and also to the understanding and meaning of learning or knowledge to the students. The deep processing activity is also found to be very minimal. From the perspective of cognitive psychology, deep processing is the heart of learning process that help students construct knowledge during information processing process (Ormrod, 2008). It is concluded that students lack deep information processing skills such as being able to connect what they are learning to daily life, and be able to produce meaningful examples to what they are learning. Thus, it is very important to equip students with the 
awareness of the process involved in the knowledge construction.

One of the important characteristic of expert learners is the ability of students to control their own learning. This process involved meta-attention and meta-comprehension. The three processes in metacognitive approach are planning, monitoring and evaluation. Most of the students reported having a specific goal at the beginning of the lesson that can help them focused and consequently monitoring and evaluating their learning outcome. However, without proper monitoring strategies, students tend to drift away from the goals of learning and could not benefit from the process. Thus, it is suggested that students should be made aware of the learning process by integrating 'learning how to learn' process to help them develop the necessary skills to learn effectively in the classroom.

From the metacognitive framework, it can be concluded that students in this study still lack metacognitive skills that are needed to help them to study effectively in the classroom. They should be guided on how to become expert learners. The process of planning, monitoring and evaluation of the process should be emphasized so that the students are aware of the strategies that can be used to take charge of their learning process while engaging cognitively with the materials under study. It is important that student be made aware of the importance of the three metacognitive processes namely planning, monitoring and evaluation in assisting them learn effectively in the classroom.

\section{CONCLUSION}

On the whole, the study found that the development of expert learners was not given enough attention by teachers in the classroom thus limiting the optimization of learning activities in the classroom. The use of metacognitive strategies is minimal and many teachers have not implement strategies to help students aware of their learning process. It can be concluded that teachers have not acknowledge and instil the importance of planning, monitoring and evaluating in students learning process. The results also provide evidence that the main issue faced by the participants of the study is the "paper chase or examination syndrome" that guides the teaching and learning activities in the classroom. Ways and means to help teachers understand the benefit of "learning to learn" process is one of the key problems need to be address in order to help students become expert learners who learn effectively in the classroom.

\section{AUTHOR INFORMATION}

Saemah Rahman is Associate Professor and Deputy Dean (UnderGraduate Studies, Alumni \& Industrial Relations) at Faculty of Education, Universiti Kebangsaan Malaysia. Her specialization is Educational Psychology. Her research interests are mainly related to Thinking Skills, Learning and Metacognition, and integration of ICT in teaching and learning.

Zuria Mahmud is Associate Professor and Deputy Dean (Post-Graduate Studies and International Relations) at Faculty of Education, Universiti Kebangsaan Malaysia. Her specialization is Counseling Education and Supervision. Her research is focused on issues related to counseling practice and training.

Siti Fatimah Mohd Yassin is senior lecturer at Faculty of Education, Universiti Kebangsaan Malaysia. Her specialization is Computer in Education and ICT and Educational Technology.

Ruslin Amir is senior lecturer at Faculty of Education, Universiti Kebangsaan Malaysia. His expertise is in Education Psychology, Counseling and Science in Education.

Khadijah Wan Ilias is post graduate student at Faculty of Education, Universiti Kebangsaan Malaysia. She is currently pursuing her doctorate degree in Educational Psychology. 


\section{REFERENCES}

1. Aronson, J., Fried, C. \& Good, C., 2002. Reducing the Effects of Stereotype Threat on African American College Students by Shaping Theories of Intelligence. Journal of Experimental Social Psychology, 38, 113125 .

2. Beyer, B.K. 1987. Improving student thinking: a comprehensive approach. Boston: Allyn \& Bacon

3. Blackwell, L., Trzesniewski, K. \& Dweck, C. S., 2007. Implicit Theories of Intelligence Predict Achievement Across an Adolescent Transition: A Longitudinal Study and an Intervention. Child Development, 78, 246-263.

4. Borkowski, J.G. \& Krause, A.J. 1985. Metacognition and Attributional Beliefs. In G. d'Ydewalle., (Eds.), Cognition, Information Processing, and Motivation. (p. 557 - 568). Amsterdam: North Holland.

5. $\quad$ Ertmer, P.A \& Newby, T.J. 1996. The expert learner: Strategic, self-regulated, and reflective, Instructional Science 24: 1-24, 1996.

6. $\quad$ Ormrod, J.E. 2008. Educational Psychology: Developing Learners. $6^{\text {th }}$ Edition. New Jersey: Pearson Prentice-Hall.

7. Schraw, G \& Brooks, D.W. 1999. Helping Students Self-regulate in Chemistry Courses: Improving the Will and The Skill. (on-line): http://www.cci.unl.edu/Chau/SelfReg.html

8. Woolfolk, A. 2008. Educational Psychology. $10^{\text {th }}$ Edition. Boston: Allyn and Bacon.

9. Zimmerman, B.J. 2002. Becoming a self-regulated learner: An overview. Theory Into Practice, 41(2), 6470. 


\section{NOTES}

